\title{
Activation of the Hypothalamic-Pituitary- Adrenocortical Axis as a Gastroprotective Component of Stress Response
}

\author{
Ludmila Filaretova \\ Laboratory of Experimental Endocrinology \\ Pavlov Institute of Physiology \\ Russia
}

\section{Introduction}

Gastric ulcer disease remains widespread; a stressful lifestyle and non-steroidal antiinflammatory drugs (NSAIDs) make significant contributions to this pathological situation (Glavin et al., 1991; Hawkey, 2000; Laine et al., 2008). Despite indubitable advances in elucidation of the pathogenesis of gastric ulceration, there are gaps in our understanding of ulcerogenesis, particularly the role of key hormonal system of adaptation: the hypothalamicpituitary-adrenocortical (HPA) axis.

\section{Glucocorticoid hormones and gastric ulceration}

Glucocorticoid hormones and gastric ulceration have been discussed in many contexts. The action of acute and chronic treatment of patients or experimental animals with glucocorticoids as well as the effects of basal and stress-induced glucocorticoid production on the gastric mucosa has been considered. Although there is a long-standing debate over whether glucocorticoid therapy by itself leads to peptic ulcer disease in human (Luo et al., 2009; Olsen et al., 2010), it is established that administration of glucocorticoids to experimental animals can result in an acute gastric erosion (Bandyopadhyay et al., 1999, as cited in Filaretova et al., 2009b; Black, 1988, as cited in Filaretova et al., 1998; Takeuchi et al., 2008). In the same time, in some cases administration of glucocorticoids to animals can attenuate gastric erosion (Derelanko \& Long 1982; Filaretova et al., 2009b; McCafferty et al., 1995). It is also known that basal glucocorticoid production contribute to the maintenance of the gastric mucosal integrity (Takeuchi et al., 1989). The glucocorticoids may modulate the cytoprotective effect of adrenal catecholamines (Hernandez et al., 1984). They may have a permissive role in allowing gastroprotective mechanisms to exert their full potential. A permissive role was suggested in gastric mucosal protection induced by prostaglandins (PGs), sulfhydryls, cimetidine (Szabo et al., 1983) or interleukin-1 (Perretti et al., 1992).

The most controversial question is the question about the action of stress-produced glucocorticoids. Based on the notion that exogenous glucocorticoids used at pharmacological doses have ulcerogenic properties, the increase of glucocorticoids during stress was also considered to be an ulcerogenic factor. In the same time, it is known that 
glucocorticoid hormones released during acute stress-induced activation of the HPA axis help the body overcome negative effects of stress stimuli (Munk et al., 1984, as cited in Filaretova et al., 1998). Despite this knowledge, it has been generally accepted for several decades that stress-produced glucocorticoids cause an ulcerogenic response in the stomach, and stress-induced activation of the HPA axis is considered a pathogenic component of this response.

As the widely held view about the ulcerogenic role of glucocorticoids released during stress is difficult to reconcile with the adaptive role of the HPA axis hormones, we designed experiments in rats to clarify the validity of this view. The results obtained do not support the traditional paradigm and suggest that glucocorticoids released during acute activation of the HPA axis are important gastroprotective factors. In the chapter, we review our results on the role of glucocorticoids in gastroprotection.

\subsection{Gastroprotective action of stress-produced glucocorticoids}

Various stressful stimuli activate the HPA axis, and consequently, the production of glucocorticoids, and severe stress stimuli may also induce gastric erosion, called "stress ulcers". Hans Selye, the "Father" of the field of research into stress, attracted attention to these signs of stress. His greatest contributions were the demonstration of the stress triad (gastrointestinal ulceration, thymico-lymphatic atrophy, and adrenal hypertrophy) and of the role of the hypothalamus in activating the hypophysis, which, in turn, stimulates the adrenals to produce corticoids (Selye, 1967). From the very outset, researchers have focused on the idea that stress-generated glucocorticoids are causally related with gastric ulcerogenesis. This possibility was also investigated in hypophysectomized and adrenalectomized animals by Selye himself, who observed that although stress-induced thymico-lymphatic atrophy was inhibited in these animals, "stress ulcers" were not prevented, and concluded that the formation of "stress ulcers" depends on not only the pituitary-adrenal axis but other factors as well. He also proposed that neurostimulators play a major role in stress-induced ulcerogenesis, although high levels of corticoids in blood could be a sensitizing factor (Selye, 1967). Weiss (Weiss, 1971, as cited in Filaretova et al., 1998) found in rats that the severity of stress-induced ulceration is positively correlated with the level of corticosterone in plasma and proposed that "steroids, in quantities that the animal is capable of secreting, may contribute to the production of ulcers". Further support for this idea came from the observation that animals with hippocampal lesions had increased levels of plasma corticosterone and developed more gastric ulcers during stress (Murphy et al., 1979, as cited in Filaretova et al., 1998). One approach used to support the view that stress-generated glucocorticoids are ulcerogenic was a groundless extrapolation of the ulcerogenic properties of exogenous glucocorticoids observed at high pharmacological doses to the properties of endogenous glucocorticoids released during stress.

From the beginning (Filaretova, 1990), we have focused on the idea that glucocorticoids released during acute stress also have an adaptive effect on the stomach and, therefore, are gastroprotective rather than ulcerogenic. To test this hypothesis, we examined the effect of glucocorticoid deficiency or the glucocorticoid receptor antagonist RU-38486 on water and immersion-restraint-induced or cold-restraint-induced gastric erosion in rats (Filaretova, 1990, 2006; Filaretova et al., 1998). Different approaches were used to inhibit the stressinduced release of corticosterone: the inhibition of corticotropin-releasing hormone synthesis in the hypothalamic paraventricular nucleus by intrahypothalamic implantation of 
dexamethasone, the immunoneutralization of ACTH by pretreatment with ACTH antiserum, and the inhibition of the HPA axis at the hypothalamic and the pituitary levels by pretreatment with a pharmacological dose of cortisol one week before stress. Corticosterone replacement, that is, the injection of corticosterone at a dose mimicking the stress-induced rise in corticosterone $(4 \mathrm{mg} / \mathrm{kg}) 15 \mathrm{~min}$ before stress, was used in our experiments.

Intrahypothalamic dexamethasone implantation significantly decreased the stressinduced increase in corticosterone and markedly provoked the gastric erosion caused by stress. Corticosterone replacement prevented the aggravating effect of dexamethasone on the ulceration. ACTH antiserum administered shortly before cold-restraint stress decreased the release of corticosterone in response to stress and enhanced the severity of the gastric erosion (Filaretova et al., 1998). Pretreatment with glucocorticoid (cortisol) at a pharmacological dose caused an inhibition of the HPA axis at the hypothalamic and pituitary levels via a negative feedback mechanism and resulted in a long-lasting decrease in the stress-induced rise in corticosterone levels (Filaretova, 2006; Filaretova et al., 2001a). It is important to emphasize that animals were stressed one week after the treatment with cortisol when the exogenous hormone had already been eliminated but the corticosterone response to stress was still inhibited. The cortisol pretreatment increased the ulcerogenic action in both models of stress, and acute corticosterone replacement that mimicked the stress-induced corticosterone response reduced gastric erosion in rats with an inhibited HPA axis (Filaretova, 1990, 2006). These results support the idea that the gastric ulcerogenic response to stress is potentiated by a reduction of stress-induced glucocorticoid production.

Glucocorticoid antagonists offer another way to demonstrate the role of the stress-induced rise in corticosterone in the gastric ulcerogenic response to stress. The specific progesterone/glucocorticoid receptor antagonist RU-38486 is known to bind with a high affinity to type II glucocorticoid receptors and may influence peripheral as well as central glucocorticoid receptors (Moguilewski \& Philibert, 1984, as cited in Filaretova et al., 1998). In the simultaneous presence of glucocorticoids and the antagonist in vivo, glucocorticoid receptors are predominantly occupied by the antagonist (Alexandrova, 1994). The RU38486-glucocorticoid receptor complex is incapable of nuclear translocation and does not produce a biological effect (Moguilewski \& Philibert, 1984, as cited in Filaretova et al., 1998). For this reason the glucocorticoid receptor antagonist RU-38486 can be a tool for investigating modes of glucocorticoid action. It was found that the occupation by RU-38486 of glucocorticoid receptors during cold-restraint stress aggravates the stress-induced gastric erosion (Filaretova et al., 1998). We believe these results support the gastroprotective role of glucocorticoids released during stress. These data also suggest that gastroprotective action of glucocorticoids may occur, at least partly, through the classical genomic mechanism. There is also evidence that glucocorticoids can act through nongenomic pathways (Whitehouse, 2011). We do not rule out that nongenomic mechanisms may also be involved in gastroprotective action of glucocorticoids.

To investigate contribution of glucocorticoids to the maintenance of gastric mucosal integrity during stress we predominantly used ulcerogenic stress models, although in some cases we also used non-ulcerogenic stress models. Using the ulcerogenic models we demonstrated that glucocorticoids released in response to the ulcerogenic stimuli attenuated their harmful action on the gastric mucosa. Our data obtained from the non-ulcerogenic 
models suggests that mild stress stimuli don't damage the gastric mucosa due to physiologic gastroprotective action of glucocorticoids released in response to these stimuli (Filaretova, 1990; Filaretova et al., 2001a). Indeed, we showed that in rats with glucocorticoid deficiency normally non-ulcerogenic stress stimulus turns into an ulcerogenic one (Filaretova, 1990). Another striking demonstration of the physiological gastroprotective role of glucocorticoids is the participation of glucocorticoids in gastroprotective effects of preconditioning stress (Filaretova et al., 2008). Preconditioning mild stress may attenuate gastric injury caused by severe stress and this effect is known to be mediated by PGs (Tanaka et al., 2007). It is known that mild stressors induce an increase in glucocorticoid production, however, it remained unknown whether glucocorticoids released during preconditioning mild stress contribute to the gasroprotective effect of mild stress against severe stressors. The contribution of glucocorticoids to the protective effect of preconditioning mild stress on gastric mucosa has not been investigated previously, apparently due to the prevailing traditional point of view on ulcerogenic action of glucocorticoids released during stress. Our findings about gastroprotective role of glucocorticoids produced during ulcerogenic stress allowed us to hypothesize that glucocorticoids contribute to gastroprotective effect of preconditioning non-ulcerogenic stress. To verify the hypothesis we compared the effects of mild stress on gastric erosion caused by severe stress in rats with normal and deficient corticosterone response to preconditioning mild stress. To inhibit glucocorticoid synthesis during mild stress metyrapone was injected shortly before the onset of mild stress. Metyrapone pretreatment caused a fast inhibition of corticosterone response to mild stress and prevented its protective effect on gastric ulceration induced by severe stress. The results obtained argue for a participation of glucocorticoids in the protective influence of preconditioning mild stress on gastric mucosa (Filaretova et al., 2008). We consider this fact as a further support for the point of view that glucocorticoids released during an acute stress are naturally occurring gastroprotective factors.

Therefore, our data allows us to conclude that an acute stress-induced increase of glucocorticoids has gastroprotective action against stress-induced gastric damage. It should be emphasized that our studies on the mode of gastroprotection by glucocorticoids have been performed on animals during acute ulceration. The effects of glucocorticoids on the gastric mucosa during chronic stress conditions may be different from those observed in acute experiments.

\subsection{Gastroprotective action of glucocorticoids during treatment with non-steroidal anti-inflammotary drugs}

According to our results (Filaretova et al., 2001b, 2002a), NSAID treatment, similar to stress, may activate the HPA axis. Administration of both indomethacin and aspirin induced a release of corticosterone, which in turn may help to protect the gastric mucosa against NSAIDs. Indeed, adrenalectomy prevented NSAID-induced corticosterone release and markedly worsened the gastric erosion caused by NSAIDs. Acute corticosterone replacement, mimicking the indomethacin- and aspirin-induced rise in corticosterone, also prevented the aggravation of gastric ulcers generated by adrenalectomy (Filaretova et al., 2002a). The aggravation of NSAID-induced gastric erosion was also demonstrated in another model of glucocorticoid deficiency where the NSAID-induced corticosterone rise was prevented by pharmacological blockade of the HPA axis (Filaretova et al., 2001b, 2005). 
Likewise, pretreatment of the animals with RU-38486, the glucocorticoid receptor antagonist, significantly aggravated the severity of gastric erosion induced by indomethacin as well as aspirin (Filaretova et al., 2002a). It is thus assumed that endogenous glucocorticoids released during NSAID treatment increase the resistance of the gastric mucosa to NSAID-induced injury.

The gastric ulcerogenic properties of NSAIDs limit the use of these drugs for the treatment of chronic inflammatory disorders, and it has been considered that combined treatment with therapeutic doses of glucocorticoid increases the risk of gastric ulceration (Hawkey, 2000). The results obtained in our studies (Filaretova et al., 2001b, 2002a, 2005) suggest that the increased risk of adverse gastric reactions should be considered when NSAIDs are used in patients with impaired glucocorticoid production.

Endogenous glucocorticoids may have a permissive role in allowing gastroprotective mechanisms against NSAID-induced injury to exert their full beneficial potential. This action was suggested in gastric mucosal protection against aspirin-induced erosion induced by cimetidine (Szabo et al., 1983) or interleukin-1 (Perretti et al., 1992). Likewise, a normal basal production of glucocorticoids is also important for the gastric mucosa to resist indomethacin- (Takeuchi et al., 1989) or aspirin-induced damage (Perretti et al., 1992). Furthermore, both aspirin and indomethacin at ulcerogenic doses stimulate glucocorticoid production to cause an acute elevation of glucocorticoid content in the physiological range, which in turn protects against gastric damage induced by these NSAIDs.

These data together with our previous findings support the point of view that glucocorticoids released during acute activation of the HPA axis caused by stress or NSAIDs as well as other ulcerogenic stimuli (Filaretova et al., 2001a) act as gastroprotective hormones. From the beginning (Filaretova, 1990), we have focused on the hypothesis that glucocorticoids released during stress also have an adaptive effect on the stomach. The results obtained in our studies confirm this hypothesis and furthermore demonstrate that glucocorticoids released in response to NSAIDs or other ulcerogenic stimuli also have an adaptive effect on the stomach. In turn, it means that an acute HPA axis activation is a physiologic gastroprotective component of acute stress response.

It is known that both humoral and neuronal factors, such as PGs, nitric oxide (NO), and capsaicin-sensitive afferent neurons, play a pivotal role in the defense against gastric mucosal injury (Holzer, 1998; Wallace, 1997). They contribute to gastroprotection by modulating mucosal blood flow, mucus secretion, and repair of injured gastric mucosa. We showed that glucocorticoids released in response to ulcerogenic stimuli are naturally occurring gastroprotective factors and exert many of the same actions in the stomach as PGs, $\mathrm{NO}$, and capsaicin-sensitive afferent neurons. This has prompted us to consider the interaction between glucocorticoid hormones and other protective factors in the maintenance of gastric mucosal integrity.

We compared the effects of the drug-induced inhibition of PG or NO production or the desensitization of capsaicin-sensitive sensory neurons on the gastric mucosa in rats with deficient or with normal glucocorticoid production, under normal or ulcerogenic conditions. Indomethacin at $35 \mathrm{mg} / \mathrm{kg}$ (s.c.) was used as an ulcerogenic stimulus. The glucocorticoid deficiency was caused by adrenalectomy one week before the experiment. Two kinds of corticosterone replacement were used in adrenalectomized rats. Indomethacin at a nonulcerogenic dose (5 mg/ kg i.p.) or L-NAME $(50 \mathrm{mg} / \mathrm{kg}$ s.c.) was acutely given to inhibit PG and NO production, respectively. For the desensitization (functional ablation) of 
capsaicin-sensitive afferent neurons, rats were given subcutaneous injections of capsaicin in 3 consecutive doses of 20,30, and $50 \mathrm{mg} / \mathrm{kg}$ (Bobryshev et al., 2005; Filaretova et al., 2007). Adrenalectomy by itself did not cause damage in the stomach. Neither inhibition of PG or $\mathrm{NO}$, nor sensory deafferentation by itself provoked any damage in the gastric mucosa of sham-operated rats. However, each of these treatments damaged the gastric mucosa in adrenalectomized rats, and all of these responses were prevented by corticosterone in drinking water at a concentration mimicking the basal corticosterone level in normal rats (Bobryshev et a., 2005; Filaretova et al., 2007).

Indomethacin-induced gastric erosion was aggravated to a similar extent by adrenalectomy, inhibition of NO production, or desensitization of capsaicin-sensitive afferent neurons. These data suggest that the role of glucocorticoid hormones in protection of the gastric mucosa against indomethacin is no less significant than that of $\mathrm{NO}$ or capsaicin-sensitive afferent neurons. The combination of adrenalectomy with inhibition of NO production or sensory deafferentation markedly potentiated the aggravating effect of these treatments by themselves on indomethacin-induced gastric erosions: the mean erosion area was increased approximately 5 or 10 times, respectively. Corticosterone at a dose mimicking the indomethacin-induced corticosterone rise totally prevented the aggravating effect of adrenalectomy in these experiments (Bobryshev et al., 2005; Filaretova et al., 2007). These results demonstrate that the effect of inhibition of NO production or sensory deafferentation on indomethacin-induced gastric erosion is significantly modified by glucocorticoid deficiency. This, in turn, suggests the important role of glucocorticoid hormones in the maintenance of gastric mucosal integrity under adverse conditions when the gastroprotective action of NO or capsaicin-sensitive neurons is impaired.

Thus, our data demonstrates a pivotal compensatory role of glucocorticoids in the maintenance of gastric mucosal integrity in the case of impaired gastroprotective mechanisms provided by PGs, NO and capsaicin-sensitive afferent neurons. The compensatory gastroprotective role of glucocorticoids during PG deficiency (Filaretova et al., 2002a) or desensitization of capsaicin-sensitive afferents (Bobryshev et al., 2005) may be provided through enhancement of their production in these situations. We also showed that glucocorticoid deficiency, in turn, induces a compensatory enhancement in PG production in the stomach through COX-2 expression, which contributes to maintain the gastric mucosal integrity (Filaretova et al., 2002b). These date allowed us to conclude that there is some cooperative interaction between glucocorticoids and PGs in gastroprotection, in a way that a deficiency of one protective factor can lead to an apparently compensatory increase of the other. The gastric mucosa becomes more susceptible to injury during deficiency of both glucocorticoids and PGs (Filaretova et al., 2002b). This finding is important for clinical practice, especially for NSAID users. This further supports a warning that the increased risk of adverse gastric reactions should be considered when NSAIDs are used in patients with impaired glucocorticoid production.

It has been suggested that "PGs, NO, and sensory neuropeptides act in concert in the maintenance of mucosal viability" (Whittle et al., 1990). The suggestion was confirmed and reinforced by other investigations. Our data adds new information to such a "concerted" modulation of the gastric mucosal integrity and suggests that glucocorticoids are also important participants in this modulation. According to the data the ability of glucocorticoids protect the gastric mucosa seems especially important for the maintenance of gastric mucosa when the protective mechanism provided by PGs or NO or capsaicin- 
sensitive afferent neurons is impared. We consider this fact as a striking manifestation of adaptive role of glucocorticoids.

\subsection{Mechanisms of gastroprotective action of glucocorticoids: the maintenance of gastric mucosal integrity through the maintenance of general body homeostasis}

There may be multiple targets for glucocorticoids to exert their beneficial influence on the gastric mucosa. We demonstrated that the gastroprotective action of glucocorticoids is provided by the maintenance of gastric mucosal blood flow, mucus secretion and repair processes as well as the attenuation of pathogenic elements such as the enhanced gastric motility (Filaretova et al., 1999, 2001b, 2002b,c, 2004). Anti-inflammatory properties of glucocorticoids may also contribute to their gastroprotective action. Glucocorticoids as antiinflammatory hormones may contribute to gastroprotection by inhibition of neutrophil adherence (Wallace, 1997) and attenuation of microvascular permeability (Filaretova et al., 2002c).

Because the glucocorticoid receptors are expressed ubiquitously it is possible that glucocorticoids may act directly on local gastric targets as well as using a more general mechanism. The contribution of glucocorticoids to the maintenance of gastric mucosal integrity may be closely related with their contribution to general body homeostasis (Filaretova et al., 2006). General homeostasis's various links can be primary targets of glucocorticoid action and, therefore, the maintenance of general body homeostasis by glucocorticoids may be the base for their action on the maintenance of gastric mucosal integrity. The following facts support this statement.

Glucocorticoids participate in maintaining normal blood glucose level that is especially important for the brain. There is a close relationship between HPA axis activity and blood glucose regulation. Hypoglycemia is the major trigger that activates the HPA axis and leads to enhancement of glucocorticoid production (Erturk et al., 1998, as cited in Filaretova et al., 2006). Glucocorticoids increase hepatic gluconeogenesis, inhibit glucose uptake in adipocytes and fibroblasts, sensitize the liver to glucagon and epinephrine, decrease the hepatic sensitivity to insulin and, as a result, they increase blood glucose level (Chan et al., 2002). In turn, maintaining the normal blood glucose level is important for the maintenance of gastric mucosal integrity. Insufficient supply of glucose may stimulate hypothalamic glucose-sensitive neurons (Mobbs et al., 2001, as cited in Filaretova et al., 2002c), resulting in a vagally-mediated increase in gastric motility and secretion (Shiraishi, 1988, as cited in Filaretova et al., 2002c) that are well-known pathogenic elements in various gastric ulcerogenic models. Exogenous glucose reverses the hypoglycemia-induced stimulation of hypothalamic glucose-sensitive neurons (Oomura et al., 1974, as cited in Filaretova et al., 2002c), inhibits vagally-mediated gastric hypermotility (Barnett \& Owyang, 1988, as cited in Filaretova et al., 2002c) and attenuates gastric ulceration (Takeuchi et al., 1990, as cited in Filaretova et al., 2002c). It was reasonable to assume that the maintenance of glucose homeostasis by glucocorticoid hormones could be fundamental to their beneficial actions on local gastric targets.

The data obtained from the model of indomethacin-induced ulceration demonstrates that the maintenance of glucose homeostasis by glucocorticoids is responsible for their beneficial actions on gastric motility. Although the mechanisms by which indomethacin induces gastric injury involves multiple, closely interacting elements such as depletion of PGs, gastric hypermotility, microcirculatory disturbances, neutrophil-endothelial cell interactions 
and superoxide radicals (Takeuchi et al., 1991; Wallace, 1997), gastric hypermotility may be a key element in the pathogenesis of indomethacin-induced gastric damage (Takeuchi et al., 1989). The glycoprivic response is involved in the mechanism of gastric hypermotility induced by NSAIDs (Mersereau \& Hinchey, 1982, as cited in Filaretova et al., 2002c). To understand the mechanisms underlying glucocorticoids' gastroprotective actions against indomethacin-induced injury, we investigated the effect of adrenalectomy, with or without corticosterone replacement, on gastric motility and blood glucose level 4 hours after administration of indomethacin at the ulcerogenic dose. We confirmed (Filaretova et al., 2002c) that indomethacin significantly enhanced gastric motility in sham-operated rats, and this hypermotility response was significantly aggravated in adrenalectomized rats, in parallel with an increase in gastric lesion score (Takeuchi et al., 1989). These results support a causal relationship between gastric hypermotility and lesion formation following administration of indomethacin. Blood glucose levels were low in adrenalectomized rats and decreased further after administration of indomethacin. This suggests a relation between low blood glucose levels, enhanced gastric motility and ulcerogenic responses to indomethacin. Indeed, adrenalectomized rats (with deficiency of corticosterone) given indomethacin showed minimum blood glucose levels, maximum gastric motility index values and maximum gastric lesion score when compared to sham-operated indomethacintreated group (Filaretova et al., 2002c). A single injection of corticosterone to adrenalectomized animals, at the dose imitating the indomethacin-induced rise in corticosterone, restored blood glucose levels and significantly reduced gastric hypermotility and ulcerogenic responses to indomethacin, whereas these beneficial effects of corticosterone was attenuated by a glucocorticoid receptor antagonist RU-38486 (Filaretova et al., 2002a,c). The findings suggest that there is close relationship between the gastroprotective action of glucocorticoids and their attenuation of gastric hypermotility through maintaining blood glucose level.

The contribution of glucocorticoids to general body homeostasis involves their beneficial influences on cardiovascular system. The major actions of glucocorticoids on cardiovascular system are to enhance vascular reactivity to other vasoactive substances and to maintain systemic blood pressure (Darlington et al., 1989, as cited in Filaretova et al., 2006; Grunfeld \& Eloy, 1987). Glucocorticoid deficiency is associated with reduced response to vasoconstrictors such as norepinephrine and angiotensin II. The latter stage of glucocorticoid deficiency is associated with cardiovascular collapse and heart failure in mammals after various stressors (Cleghorn, 1983, as cited in Filaretova et al., 2006). Glucocorticoid replacement is crucial in the treatment of patients with adrenal crisis, including the patients with Addison's disease (Darlington et al., 1989, as cited in Filaretova et al., 2006). On the contrary, glucocorticoid excess induces hypertension in human and rats. Hypertension is seen in patients with excessive glucocorticoid secretion, occurring in most patients with Cushing's syndrome and in patients with glucocorticoid treatment (Nieman et al., 1985, as cited in Filaretova et al., 2006). It was reported that a patient with Cushing's syndrome was treated successfully with glucocorticoid receptor antagonist RU-38486 at high dose (Nieman et al., 1985, as cited in Filaretova et al., 2006). Experimental data obtained in adrenalectomized animals with or without glucocorticoid replacement (Darlington et al., 1989; Darlington \& Tehrani, 1997, as cited in Filaretova et al., 2006) as well as in rats with occupation of glucocorticoids receptors by RU-38486 (Grunfeld \& Eloy, 1987, as cited in Filaretova et al., 2006) confirm and further develop clinical observations about the important contribution of glucocorticoid hormones to the regulation of blood pressure. 
Under certain conditions, maintaining blood pressure is especially important for the maintenance of gastric mucosal integrity. There is evidence showing the linear correlation between the graded systemic hypotension and the mucosal blood flow as an important defensive factor (Guth, 1992). It was hypothesized that the blood flow to the stomach, a nonessential organ, decreases more rapidly and at an early stage of graded hypotension, in order to maintain blood flow to the essential organs such as the brain and kidney. The decrease in submucosal and mucosal blood flow during stress is an important factor, leading to mucosal ischemia, impairment in tissue resistance, and subsequent ulceration in stressed animals (Guth, 1992; Tarnasky et al., 1990). These facts allow us to assume that maintaining systemic blood pressure by glucocorticoids may be fundamental to their beneficial action on gastric blood flow and, consequently, on gastric mucosal integrity.

Utilizing an in vivo microscopy technique for the direct visualization of the gastric microcirculation (Filaretova et al., 1999) as well as methods creating the alterations in glucocorticoid supply, we examined whether gastric microcirculation and arterial blood pressure are involved in the mechanism of gastroprotective action of glucocorticoids during 3 hour water immersion-restraint stress. To this end the effects of deficiency of glucocorticoid production followed by corticosterone replacement on the stress-induced gastric microcirculation, systemic arterial pressure and gastric erosion were investigated. The stress-induced glucocorticoid production was inhibited by a single high dose of cortisol injected one week before stress. Gastric microcirculation was evaluated by measurement of the blood flow velocity in submucosal and mucosal microvessels (Filaretova et al., 1999).

Water immersion-restraint stress caused decrease in blood flow velocity in submucosal and mucosal gastric microvessels. The deficiency of glucocorticoids during water immersionrestraint stress promoted the stress-induced decrease of blood flow velocity in submucosal and mucosal microvessels, and corticosterone replacement prevented this effect (Filaretova et al. 1999, 2004). The results suggest that glucocorticoids released during water immersionrestraint stress maintain gastric blood flow during the stress. Our data also confirms that the decrease in gastric blood flow is associated with the reduction in systemic blood pressure. Mean systemic blood pressure in stressed rats with glucocorticoid deficiency was about 60 $\mathrm{mm} \mathrm{Hg}$, and these animals had a very low gastric blood flow velocity and large erosion area. Corticosterone replacement increased both systemic blood pressure and gastric blood flow and, as a result, improved the resistance of gastric mucosa to ulcerogenic stress action. It means that the improvement of gastric blood supply by glucocorticoids is provided, at least partly, through their beneficial action on systemic blood circulation. The data suggests that the gastroprotective actions of glucocorticoids during water immersion-restraint stress may be provided by the maintenance of gastric blood flow that may be brought about by their beneficial effect on arterial blood pressure (Filaretova et al. 1999, 2004).

Thus, glucocorticoids released during activation of the HPA axis may contribute to protection of the gastric mucosa by maintaining general body homeostasis, including glucose levels and systemic blood pressure, which could be a basis for their beneficial influence on gastric mucosal integrity.

\subsection{How gastroprotective action of glucocorticoids may be transformed to proulcerogenic one}

Thus, in general glucocorticoid hormones may have dual action on the stomach: physiological gastroprotective and pathological proulcerogenic one. In al physiologic 
conditions, even in acute stress situations, glucocorticoids have an adaptive effect on the stomach and, therefore, are gastroprotective, while in some situations their action on the gastric mucosa may become proulcerogenic. It is important to understand how physiological gastroprotective action can be transformed to pathological proulcerogenic effect.

Because the maintenance of glucose homeostasis by glucocorticoids could be fundamental to their gastroprotective action (Filaretova et al., 2002c, 2006), it was reasonable to assume that glucocorticoid-induced disturbance of glucose regulation, observed in clinical and experimental situations (Subramanian \& Trence, 2007, as cited in Filaretova et al., 2009a), may contribute to ulcerogenic action of glucocorticoids on the gastric mucosa. We supposed that short-term maintenance of blood glucose level provides the gastroprotective action of glucocorticoids, while long-lasting maintenance of blood glucose level or long-lasting hyperglycemia through a disturbance of carbohydrate regulation may account, at least partly, for the ulcerogenic action of glucocorticoids. Thus, we hypothesized that glucocorticoid-induced long-lasting maintenance of blood glucose level accompanied by their catabolic effects may be responsible for the transformation of gastroprotective action of glucocorticoids to their proulcerogenic effect.

We verified the hypothesis investigating the effects of exogenous glucocorticoid and dexamethasone was selected for this aim as synthethic long-acting glucocorticoid. Stress and indomethacin were used as ulcerogenic stimuli because both of them are considered as most significant ulcerogenic factors in human (Laine et al., 2008). It is important to note that both stimuli were applied to rats after 24 hour fasting. Taking into consideration that action of exogenous glucocorticoids on the gastric mucosa is depended on the dose (Laine et al., 2008) first, we investigated dose-dependent effects of dexamethasone. Surprisingly, dexamethasone, even at pharmacological dose $10 \mathrm{mg} / \mathrm{kg}$ protected the gastric mucosa against stress- and indomethacin-induced injury, at least, during first hour of its action (Filaretova et al., 2009a,b).

Because dexamethasone at the dose of $1 \mathrm{mg} / \mathrm{kg}$ decreased the gastric erosion area and maintained blood glucose level in fasted stressed or indomethacin-pretreated rats (in the case of its injection $1 \mathrm{~h}$ before the onset of cold-restraint or indomethacin administration) this dose has been selected for the next step, time-dependent study. The results obtained demonstrate that single injection of dexamethasone at a dose of $1 \mathrm{mg} / \mathrm{kg}$ may attenuate or aggravate both cold-restraint- and indomethacin-induced gastric erosion depending on the duration of its action before the onset of the stress or indomethacin, respectively. Shortlasting (1-12 hours) action of dexamethasone attenuated cold-restraint- and indomethacininduced gastric ulceration. However long-lasting (21-24 hours) dexamethasone action resulted in an aggravation of cold-restraint- and indomethacin-induced gastric erosion (Filaretova et al., 2009a,b). The findings suggest that manifestation of gastroprotective or ulcerogenic action of glucocorticoids used at the same dose may be dependent very much on the time interval between the hormonal injection and onset of ulcerogenic stimulus. Prolongation of dexamethasone action may lead to enhancement of gastric mucosal susceptibility to ulcerogenic action of cold-restaint or indomethacin.

Both short- and long-lasting dexamethasone actions resulted in maintenance of blood glucose level in fasted stressed and indomethacin-treated rats. Dexamethasone-induced long-lasting maintenance of blood glucose level accompanied with the signs of catabolic effects. It should be note that dexamethasone-induced increase in the lost of body weight 
during fasting preceded the appearance of its ulcerogenic action. Thymus weight was used as another marker of dexamethasone-induced catabolic effects. It is known that glucocorticoids at pharmacological doses tend to kill off many of the thymus cells. This phenomenon is the basis for the immunosuppressive use of glucocorticoids (Young et al., 1981, as cited in Filaretova et al., 2009a). It was shown that dexamethasone accelerates the rate of apoptosis in thymocytes (de Belle et al., 1994, as cited in Filaretova et al., 2009a). According to our data in distinguish from the body weight changes the thymus weight changes started earlier. These findings are in agreement with the data of literature showed that metabolic glucocorticoid effects in thymus cells evolve more rapidly comparing those in other target cells. The most prominent effect of glucocorticoid in thymus cells is a large inhibition of glucose transport that reaches $25-30 \%$ by about $30 \mathrm{~min}$ after the hormone addition. The metabolic inhibitions followed by cell destruction (Young et al., 1981, as cited in Filaretova et al., 2009a).

Dexamethasone treatment inhibited cold-restaint- and indomethacin-induced corticosterone production. Because according to our data deficiency of corticosterone aggravates cold-restaint- and indomethacin-induced gastric erosion, it is quite possible that simultaneous corticosterone deficiency and consequences of disturbances of carbohydrate regulation contributed together to proulcerogenic effect of long-lasting dexamethasone treatment.

We prolonged our study till the 7th day to clarify the questions how long dexamethasone effects may be continued and whether they are reversible. It was found that the dexamethasone-induced proulcerogenic action was continued till the 5th day and then, on the 7th day was disappeared. The restoration of stress- or indomethacin-induced corticosterone production, which preceded the restoration of normal susceptibility of the gastric mucosa to ulcerogenic action of cold-restraint, may contribute to this event. The gradual restoration of normal body and spleen weight is a good symptom of reversibility dexamethasone-induced catabolic effects. Disappearance of dexamethasone-induced maintenance of blood glucose level preceded the restoration of normal body and spleen weight.

In our experimental situations the transformation of gastroprotective action of dexamethasone to proulcerogenic one occurred $18 \mathrm{~h}$ after its administration, but it is clear that in general this time interval depends on many factors, including a kind of glucocorticoid and its dose, a specificity of situation. As far back as 1950 it was noted on the base of clinical observations that it needs at least 5-7 days of corticosteroids use before appearance of ulcer symptoms (Sandweiss, 1954, as cited in Filaretova et al., 2009a). One of the principles for minimizing undesirable side effects of glucocorticoid therapy is "keep treatment as short as possible, since treatment lasting 5 to 7 days shows fewer side effects" (Longui, 2007, as cited in Filaretova et al., 2009a). It is more often glucocorticoid-induced ulcer symptoms appeared after much more long hormonal treatment. Our results allow us to speculate that glucocorticoid-induced disturbance of carbohydrate regulation, which needs time for developing, contributes to appearance of ulcer symptoms after long-lasting hormonal therapy. It means that control of glucose regulation and its correction in case of need may be considered as useful approach minimizing ulcerogenic side effect of glucocorticoid therapy.

In conclusion, the data obtained so far suggest that short-lasting maintenance of blood glucose levels may be responsible for the gastroprotective action of glucocorticoids, while 
glucocorticoid-induced long-lasting maintenance of blood glucose levels accompanied with the signs of their catabolic effect and glucocorticoid-induced corticosterone deficiency may be responsible, at least partly, for the transformation of gastroprotective action of glucocorticoids to their proulcerogenic effect (Filaretova et al. 2009a, 2009b). Further investigation of detailed mechanisms underlying proulcerogenic glucocorticoid action is the task of our future studies. We take into consideration other, additional, possibilities for explanation the question how physiological gastroprotective action can be transformed to pathological proulcerogenic effect.

\section{Conclusion}

According to our data an acute stress-induced increase of glucocorticoids has a gastroprotective action against stress-induced gastric injury but is not ulcerogenic, as it has generally been considered for some decades. Beneficial action of high levels of endogenous glucocorticoids released during acute stress on the stomach is opposite to the harmful actions of exogenous glucocorticoids at pharmacological doses used as a hormonal therapy. NSAIDs as well as other ulcerogenic stimuli, similar to stress, induce an increase in glucocorticoid production that in turn helps the gastric mucosa to resist the harmful actions of these stimuli. It is assumed that the adaptive action of glucocorticoids released during acute activation of the HPA axis may be applied to the gastric mucosa. Glucocorticoids exert gastroprotective actions in co-operation with PGs, NO and capsaicin-sensitive sensory neurons: their compensatory gastroprotective action is observed when the protective mechanism provided by either of these factors is impared. Gastroprotective effects of glucocorticoids may be mediated by multiple actions, including maintenance of gastric mucosal blood flow, mucus production, and attenuation of enhanced gastric motility and microvascular permeability. The contribution of glucocorticoids to gastroprotection is tightly related with their contribution to general body homeostasis. Glucocorticoids released during activation of the HPA axis may contribute to protection of the gastric mucosa by maintaining general body homeostasis, including glucose levels and systemic blood pressure, which could be a basis for their beneficial influence on gastric mucosal integrity. These findings further support idea that gastroprotective action of glucocorticoids is an essential element of their general adaptive action. In conclusion, the results obtained in our studies suggest that glucocorticoids released during acute activation of the HPA axis are naturally occurring protective factors that play an important role in maintenance of the gastric mucosal integrity. In turn, it means that acute activation of the HPA axis is a gastroprotective component of stress response.

\section{Acknowledgment}

I would like to show my thanks to Professor A. Filaretov for supporting this field of research in the very beginning; to my colleagues Dr. T. Podvigina, Dr. P. Bobryshev, Dr. T. Bagaeva, Dr. O. Morozova and my long-standing assistance Mrs. T. Kolbasova for their active participation in developing this research study; to Professor G. Makara from the Institute of Experimental Medicine (Budapest) and Professor K. Takeuchi from the Kyoto Pharmaceutical University for making it possible to continue this research in their laboratories and for their kind support. This study was supported by grants of RFBR-10-0400605; FNM RAS-2009-2011; DBS RAS-2009-2011. 


\section{References}

Alexandrova, M. (1994). Stress induced tyrosine aminotransferase activity via glucocorticoid receptor. Horm Metab Res, Vol.26, No.2, (February 1994), pp. 97-99, ISSN 0170-5903

Bobryshev, P.Yu., Bagaeva, T.R., Podvigina, T.T. \& Filaretova, L. (2005). Gastroprotective action of glucocorticoid hormones in rats with desensitization of capsaicin-sensitive sensory neurons. Inflammopharmacology, Vol.13, No.1-3, (February 2005), pp. 217228, ISSN 0925-4692

Chan, O., Chan, S., Inouye, K., Shum, K., Matthews, S.G. \& Vranic, M. (2002). Diabetes impairs hypothalamo-pituitary-adrenal (HPA) responses to hypoglycemia, and insulin treatment normalizes HPA but not epinephrine responses. Diabetes, Vol.51, No.6, (June 2002), pp. 1681-1689, ISSN 0012-1797

Derelanko, M. J. \& Long, J. F. (1982). Influence of prednisolone on ethanol-induced gastric injury in the rat. Dig Dis Sci, Vol.27, No.2, (February 1982), pp. 149-154, ISSN 01632116

Filaretova, L. (1990). The dependence of the formation of stress gastric ulcers on the function of hypothalamo-hypophyseal-adrenocortical system. Sechenov Physiol J USSR, Vol.76, No.11, (November 1990), pp. 1594-1600, ISSN 0015-329X

Filaretova, L.P. (2006). The hypothalamic-pituitary-adrenocortical system: hormonal braingut interaction and gastroprotection. Autonomic Neurosci: Basic and Clinical, Vol.125, No.1-2, (April 2006), pp. 86-93, ISSN 1566-0702

Filaretova, L.P., Bagaeva, T.R. \& Makara, G.B. (2002a). Aggravation of nonsteroidal antiinflammatory drug gastropathy by glucocorticoid deficiency or blockade of glucocorticoid receptor in rats. Life Sci, Vol.71, No.21, (October 2002), pp. 2457-2468, ISSN 0024-3205

Filaretova, L.P., Filaretov, A. \& Makara, G.B. (1998). Corticosterone increase inhibits stressinduced gastric erosions in rats. Am J Physiol, Vol.274, No.6, (June 1998), pp. G1024G1030, ISSN 0193-1857

Filaretova, L., Bagaeva, T., Amagase, K. \& Takeuchi, K. (2008). Contribution of glucocorticoids to protective influence of preconditioning mild stress against stressinduced gastric erosions. Ann N Y Acad Sci, Vol.1148, (December 2008), pp. 209-212, ISSN 0077-8923

Filaretova, L., Bagaeva, T., Podvigina, T. \& Makara, G. (2001a). Various ulcerogenic stimuli are potentiated by glucocorticoid deficiency in rats. J Physiol Paris, Vol.95, No.1-6, (January-December 2001), pp. 59-65, ISSN 0928-4257

Filaretova, L.P., Maltcev, A.N., Bogdanov, A.I. \& Levkovich, Yu.I. (1999). Role of gastric microcirculation in the gastroprotection by glucocorticoids released during waterrestraint stress in rats. Chin J Physiol, Vol.42, No.3, (September 1999), pp. 145-152, ISSN 0304-4920

Filaretova, L., Morozova, O., Bagaeva, T. \& Podvigina T. (2009a). From gastroprotective to proulcerogenic action of glucocorticoids on the gastric mucosa. J Physiol Pharmacol, Vol.60, Supp.1 7, (December 2009), pp. 79-86, ISSN 0867-5910

Filaretova, L., Podvigina, T., Bagaeva, T. \& Makara G. (2001b). Gastroprotective action of glucocorticoids during the formation and the healing of indomethacin-induced 
gastric erosions in rats. J Physiol Paris, Vol.95, No.1-6, (January-December 2001), pp. 201-208, ISSN 0928-4257

Filaretova, L., Podvigina, T., Bagaeva, T. \& Morozova, O. (2009b). Dual action of glucocorticoid hormones on the gastric mucosa: how the gastroprotective action can be transformed to the ulcerogenic one. Inflammopharmacology, Vol.17, No.1, (February 2009), pp. 15-22, ISSN 0925-4692

Filaretova, L., Tanaka A., Komoike, Y. \& Takeuchi, K. (2002b). Selective cyclooxygenase-2 inhibitor induces gastric mucosal damage in adrenalectomized rats. Inflammopharmacology, Vol.10, No.4-6, pp. 413-422, ISSN 0925-4692

Filaretova, L., Bobryshev, P., Bagaeva, T., Podvigina, T. \& Takeuchi K. (2007). Compensatory gastroprotective role of glucocorticoid hormones during inhibition of prostaglandin and nitric oxide production and desensitization of capsaicin-sensitive sensory neurons. Inflammopharmacology, Vol.15, No.4, (August 2007), pp. 146-153, ISSN 0925-4692

Filaretova, L.P., Podvigina, T.T., Bagaeva, T.R., Tanaka, A. \& Takeuchi, K. (2005). Gastroprotective action of glucocorticoid hormones during NSAID treatment. Inflammopharmacology, Vol.13, No.1-3, (February 2005), pp. 27-43, ISSN 0925-4692

Filaretova, L.P., Podvigina, T.T., Bagaeva, T.R., Tanaka A. \& Takeuchi K. (2004). Mechanisms underlying gastroprotective action of glucocorticoids released in response to ulcerogenic stress factors. Ann NY Acad Sci, Vol.1018, (June 2004), pp. 288-293, ISSN 0077-8923

Filaretova, L., Podvigina, T., Bobryshev, P., Bagaeva, T., Tanaka, A. \& Takeuchi K. (2006). Hypothalamic-pituitary-adrenocortical axis: the hidden gold in gastric mucosal homeostasis. Inflammopharmacology, Vol. 14, No.5-6, (December 2006), pp. 207-213, ISSN 0925-4692

Filaretova, L., Tanaka, A., Miyazawa, T., Kato, S. \& Takeuchi K. (2002c). Mechanisms by which endogenous glucocorticoids protects against indomethacin-induced gastric injury in rats. Am J Physiol, Vol.283, No.5, (November 2002), pp. G1082-G1089, ISSN 0193-1857

Glavin, G.B., Murison, R., Overmier, J.B., Pare, W.P., Bakke, H.K., Henke, P.G. \& Hernandez, D.E. (1991). The neurobiology of stress ulcers. Brain Res Brain Res Rev, Vol.16, No.3, (September-December 1991), pp. 301-343.

Guth, P.H. (1992). Current concept in gastric microcirculatory pathophysiology. Yale J Biol Med, Vol.65, No.6, (November-December 1992), pp. 677-688, ISSN 0044-0086

Hawkey, C.J. (2000). Nonsteroidal anti-inflammatory drug gastropathy. Gastroenterology, Vol.119, No.2, (August 2000), pp. 521-535, ISSN 0016-5085

Hernandez, D.E., Adcock, J.W., Nemeroff, C.B., Prange \& A.J. Jr. (1984). The role of the adrenal gland in cytoprotection against stress-induced gastric ulcers in rats. $J$ Neurosci Res, Vol.11, No. 2, pp. 193-201, ISSN 0360-4012

Holzer, P. (1998). Neural emergency system in the stomach. Gastroenterology, Vol.114, No.4, (April 1998), pp. 823-839, ISSN 0016-5085

Laine, L., Takeuchi, K. \& Tarnawski, A. (2008). Gastric mucosal defense and cytoprotection: bench to bedside. Gastroenterology, Vol.135, No.1, (July 2008), pp. 41-60, ISSN 00165085 
Luo, J.C., Chang, .F.Y., Chen, T.S., Ng, Y.Y., Lin, H.C., Lu, C.L., Chen, C.Y., Lin, H.Y. \& Lee S.D. (2009). Gastric mucosal injury in systemic lupus erythematosus patients receiving pulse methylprednisolone therapy. Br J Clin Pharmacol, Vol.68, No.2, (August 2009), pp. 252-259, ISSN 0306-5251

McCafferty, D.M., Granger, D.N. \& Wallace, J.L. (1995). Indomethacin-induced gastric injury and leukocyte adherence in arthritic versus healthy rats. Gastroenterology, Vol.109, No.4, (October 2005), pp. 1173-1180, ISSN 0016-5085

Olsen, M., Christensen, S., Riis, A. \& Thomsen, R.W. (2010). Preadmission use of systemic glucocorticoids and 30-day mortality following bleeding peptic ulcer: a populationbased cohort study. Am J Ther, Vol.17, No.1, (January-February 2010), pp. 23-29, ISSN 1075-2765

Perretti, M., Mugridge, K.G., Wallace, J.L. \& Parénte, L. (1992). Reduction of aspirininduced gastric damage in rats by interleukin-1 beta: possible involvement of endogenous corticosteroids. J Pharmacol Exp Ther, Vol.61, No.3, (June 1992), pp. 1238-1247, ISSN 0022-3565

Selye, H. (1967) In Vivo. The case for supramolecular biology presented in six informal, illustrated lectures. Liveright, New York, US

Szabo, S., Callagher, G.T., Horner, H.C., Frankel, P.W., Underwood, R.H., Konturek, S.J., Brzozowski T. \& Trier JS. (1983). Role of the adrenal cortex in gastric mucosal protection by prostaglandins, sulfhydryls, and cimetidine in the rat. Gastroenterology, Vol.85, No.6, (December 1983), pp. 1384-1390, ISSN 0016-5085

Takeuchi, Y., Takahashi, M. \& Fuchikami, J. (2008) Vulnerability of gastric mucosa to prednisolone in rats chronically exposed to cigarette smoke. J Pharmacol Sci, Vol.106, No.4, (April 2008), pp. 585-592, ISSN 1347-8613

Takeuchi, K., Nishiwaki, H., Okada, M., Niida, H. \& Okabe, S. (1989). Bilateral adrenalectomy worsens gastric mucosal lesions induced by indomethacin in the rat. Role of enhanced gastric motility. Gastroenterology, Vol.97, No.2, (August 1989), pp. 284-293, ISSN 0016-5085

Takeuchi, K., Ueshima, K., Hironaka, Y., Fujioka, Y., Matsumoto, J. \& Okabe S. (1991). Oxygen free radicals and lipid peroxidation in the pathogenesis of gastric mucosal lesions induced by indomethacin in rats. Digestion, Vol.49, No.3, pp. 175-184, ISSN 0012-2823

Tanaka, A., Hatazawa, R., Takahira, Y., Izumi, N., Filaretova, L. \& Takeuchi, K. (2007) Preconditioning stress prevents cold restraint stress-induced gastric lesions in rats: roles of COX-1, COX-2, and PLA2. Dig Dis Sci, Vol.52, No.2, (February 2007), pp. 478-487, ISSN 0163-2116

Tarnasky, P.R., Livingston, E.H., Jacobs, K.M., Zimmerman, B.J., Guth, P.H. \& Garrick, T.R. (1990). Role of oxyradicals in cold water immersion restraint-induced gastric mucosal injury in the rat. Dig Dis Sci, Vol.35, No.2, (February 1990), pp. 173-177, ISSN 0163-2116

Wallace, J.L. (1997). Nonsteroidal anti-inflammatory drugs and gastroenteropathy: the second hundred years. Gastroenterology, Vol.112, No.3, (March 1997), pp. 1000-1016, ISSN 0016-5085 
Whitehouse, M.W. (2011). Anti-inflammatory glucocorticoid drugs: reflections after 60 years. Inflammopharmacology, Vol.19, No.1, (February 2011), pp. 1-19, ISSN 09254692

Whittle, B.J.R., Lopez-Belmonte, J. \& Moncada, S. (1990). Regulation of gastric mucosal integrity by endogenous nitric oxide: interactions with prostanoids and sensory neuropeptides in the rats. Br J Pharmacol, Vol.99, No.3, (March 1990), pp. 606-611, ISSN 0007-1188 


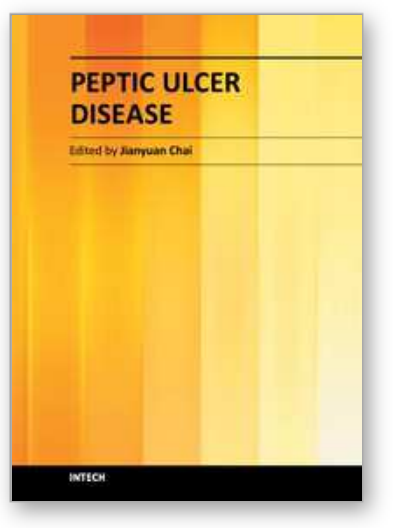

\author{
Peptic Ulcer Disease \\ Edited by Dr. Jianyuan Chai
}

ISBN 978-953-307-976-9

Hard cover, 482 pages

Publisher InTech

Published online 04, November, 2011

Published in print edition November, 2011

Peptic ulcer disease is one of the most common chronic infections in human population. Despite centuries of study, it still troubles a lot of people, especially in the third world countries, and it can lead to other more serious complications such as cancers or even to death sometimes. This book is a snapshot of the current view of peptic ulcer disease. It includes 5 sections and 25 chapters contributed by researchers from 15 countries spread out in Africa, Asia, Europe, North America and South America. It covers the causes of the disease, epidemiology, pathophysiology, molecular-cellular mechanisms, clinical care, and alternative medicine. Each chapter provides a unique view. The book is not only for professionals, but also suitable for regular readers at all levels.

\title{
How to reference
}

In order to correctly reference this scholarly work, feel free to copy and paste the following:

Ludmila Filaretova (2011). Activation of the Hypothalamic-Pituitary-Adrenocortical Axis as a Gastroprotective Component of Stress Response, Peptic Ulcer Disease, Dr. Jianyuan Chai (Ed.), ISBN: 978-953-307-976-9, InTech, Available from: http://www.intechopen.com/books/peptic-ulcer-disease/activation-of-the-hypothalamicpituitary-adrenocortical-axis-as-a-gastroprotective-component-of-stre

\section{INTECH}

open science | open minds

\author{
InTech Europe \\ University Campus STeP Ri \\ Slavka Krautzeka 83/A \\ 51000 Rijeka, Croatia \\ Phone: +385 (51) 770447 \\ Fax: +385 (51) 686166 \\ www.intechopen.com
}

\author{
InTech China \\ Unit 405, Office Block, Hotel Equatorial Shanghai \\ No.65, Yan An Road (West), Shanghai, 200040, China \\ 中国上海市延安西路65号上海国际贵都大饭店办公楼405单元 \\ Phone: +86-21-62489820 \\ Fax: +86-21-62489821
}


(C) 2011 The Author(s). Licensee IntechOpen. This is an open access article distributed under the terms of the Creative Commons Attribution 3.0 License, which permits unrestricted use, distribution, and reproduction in any medium, provided the original work is properly cited. 